\title{
Participação em saúde: do que estamos falando? ${ }^{1}$
}

Resumo

\section{MARIA LUCIA TEIXEIRA \\ WERNECK VIANNA* \\ MARIA DE LOURDES \\ CAVALCANTI \\ MARTA DE PINA CABRAL}

Artigo elaborado no âmbito do projeto Gestão Participativa em Saúde: estudo e sistematização da produção acadêmica e das experiências de conselhos e conferências de saúde, em desenvolvimento no Laboratório de Economia Política da Saúde da UFRJ. Traz algumas reflexões a respeito do estatuto do conceito de participação no campo das ciências sociais, sob uma perspectiva histórica, na tentativa de desenhar um pano de fundo que permita compreensão mais acurada do uso recente e recorrente desse conceito, bem como de sua avassaladora incorporação ao universo da saúde. São formulações de caráter provisório expostas com intuito de suscitar debate e contribuir na elucidação das indagações sobre as possibilidades e limites das instâncias de controle social do Sistema Ú nico de Saúde. Em seguida, apresenta análise preliminar da revisão dos artigos da área de Saúde Coletiva, publicados no Brasil ao longo das duas últimas décadas, sobre "participação social e saúde", ou seja, que enfocam os mecanismos de participação da sociedade no sistema de saúde, entre eles os conselhos criados (ou institucionalizados) a partir da lei 8142 de dezembro de 1990. Possui um caráter preliminar, por se tratar

* Cientista Social, doutora e professora adjunta do Instituto de Economia e pesquisadora do Laboratório de Economia Política da Saúde (LEPS - UFRJ).

10 artigo contou com a estreita colaboração das professoras M aria de Lourdes Tavares Cavalcanti e Ludmila Antunes, doutoras e pesquisadoras associadas do LEPS. Contou, ainda, com o inestimável trabalho de Marta Henriques de Pina Cabral, Fabiana de Souza Faria e Isabel Mansur, mestrandas do Instituto de Estudos de Saúde Coletiva da UFRJ, Julia Polessa, mestranda do Instituto de Filosofia e Ciências Sociais da UFRJ, e Fabiana Dutra, estagiária do Laboratório de Economia Política da Saúde da UFRJ. 
de pesquisa em desenvolvimento e por expor considerações não amadurecidas por completo no intuito de suscitar debate.

Palavras-chave: Participação política. Participação social. Participação e saúde. Conselhos de saúde.

\section{Introdução}

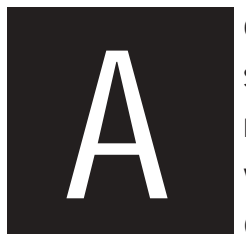

o longo dos 16 anos de implementação do SUS, os Conselhos de Saúde e as conferências de saúde consolidaram-se como espaços de mediação, participação e intervenção de interesses e valores diversificados e plurais. Contudo, o desempenho desses fóruns, ora imersos num debate sobre a negociação caso a caso da alocação de recursos financeiros, ora desconcertados diante de uma imensa pauta de problemas gerais - não hierarquizados, não resolvidos e reapresentados constantemente de maneira cumulativa -, traz de volta a velha dúvida: tratar-se-ia de uma potência decisória ilusória?

Este artigo faz algumas reflexões a respeito do estatuto do conceito de participação no campo das ciências sociais. A despeito de um certo abuso do recurso à história das idéias, a tentativa é de desenhar um pano de fundo que permita compreensão mais acurada do uso recente e recorrente desse conceito, bem como de sua avassaladora incorporação ao universo da saúde.

Na próxima sessão, formulações de caráter provisório são expostas com o intuito de suscitar debate e na expectativa de que ajudem a elucidar as indagações sobre as possibilidades e limites das instâncias de participação do Sistema Ú nico de Saúde (SUS). A seguir, apresenta-se uma breve revisão (também preliminar) de artigos publicados no Brasil ao longo das duas últimas décadas sobre "participação social em saúde", ou seja, artigos que enfocam os mecanismos de participação da sociedade no sistema 
de saúde, entre eles os conselhos criados (ou institucionalizados) a partir da lei 8142 de $1990^{2}$.

\section{Participação: em busca de um marco teórico}

Participação - social, da comunidade -, controle social (leia-se da sociedade), gestão participativa. A legislação brasileira institucionaliza a prática participativa com a Lei n 8.142 que dispõe sobre a participação da comunidade na gestão do Sistema Ú nico de Saúde e sobre as transferências intergovernamentais de recursos financeirose dá outras providências, bem como institui, sem prejuízo das funções do Poder Legislativo, as instâncias colegiadas de participação, conferências e conselhos de saúde, atribuindo-Ihes papéis deliberativos e fiscalizadores. 0 cumprimento desses papéis tem sido examinado por uma pujante literatura na área de saúde coletiva, literatura que busca principalmente avaliar ou discutir a efetividade das instâncias criadas para dar voz à chamada sociedade civil, em especial os Conselhos M unicipais de Saúde.

Contudo, para o cientista social, uma questão mais abrangente precede a avaliação da efetividade dos Conselhos (e outros fóruns de participação) como esferas simultaneamente de representação das partes envolvidas com as políticas de saúde, e de exercício direto da cidadania pela população. Resumida na indagação "o que é - ou o que está sendo entendido como participação?", a questão se desdobra em outras perguntas também anteriores à análise da efetividade de um determinado arranjo participativo. Q ue processos devem ser considerados como participatórios: a escolha de representantes (e por quais vias) ou a expressão direta de demandas (individuais ou coletivas)? Q ue dimensões da vida social devem

2 Por necessidade de limitar o escopo do artigo foram selecionados apenas artigos da área de Saúde Coletiva. 
ser destacadas para que se identifique a ação participativa? Enfim, em termos teóricos, como definir participação?

Desde logo, vale uma sumaríssima nota metodológica. Definir é um verbo de conjugação duvidosa no campo das Ciências Sociais. Entre cientistas sociais, há convergências mais ou menos estabelecidas em torno de alguns conceitos, mas dificilmente se abre mão da expressão "segundo tal ou qual autor", ou da análoga "conforme tal ou qual abordagem", para usá-los. Definições de participação que ultrapassem a óbvia perspectiva da semântica vernacular - tomar parte -, requerem a identificação de diferentes quadros de fundamentação teórica, quadros esses formulados em também diferentes contextos históricos. $\mathrm{O}$ u seja, é pertinente afirmar que não há, a priori, um marco teórico no qual incluir o conceito de participação. Esforços realizados por pesquisad ores da área da saúde no sentido de situar teoricamente o conceito parecem confirmar essa afirmativa.

Assim, Cortes (1996a, 73) procura mostrar como a questão da participação é tratada, de modo diferenciado, por " praticamente todas as correntes de pensamento político e sociológico. Seguindo a tendência taxonomista da ciência social americana, a autora apresenta as cinco correntes de pensamento que analisam o papel do Estado em sociedades modernas: o pluralismo, a teoria das elites, a nova direita, o marxismo e o neopluralismo". Deixando de lado a discussão que a própria classificação suscita ${ }^{3}$, a revisão de Co RTEs (1996a) sugere a impossibilidade de se entender o sentido do conceito de participação sem inseri-lo numa dada corrente teórica. Entretanto, a autora enfatiza mais a dimensão propositiva das correntes examinadas do que os fundamentos que oferecem para a elucidação do conceito de participação.

3 Considerar o pluralismo como corrente de pensamento alternativa ao marxismo ou mesmo à chamada teoria das elites faz parte do etnocentrismo da ciência social americana. 0 pluralismo consiste na descrição valorada de uma situação, a americana, e, no caso dos pluralistas mais consistentes (D ahl e Lindblom, por exemplo), numa tomada de posição. Ver Dahl, R. Dilemmas 
pode-se identificar duas propostas básicas de intensificação da participação nas democracias liberais. A primeira, defendida pelos teóricos da nova direita, preconiza a ampliação do direito de escolha do participante, concebido como consumidor de bens e serviços oferecidos por uma multiplicidade de produtores e prestadores, preferencialmente privados. A segunda, defendida por uma parcela dos marxistas e dos neopluralistas, propõe a criação de mecanismos participatórios que venham a ampliar o direito dos cidadãos em influenciar o processo de decisão política (CORTES, 1996a, 75).

Gascón, Tamargo ; Carles $(2005,2)$ também reconhecem que participação é um conceito "através do qual se podem perceber as transformações nos contextos históricos, econômicos, políticos e sociais nos quais a noção de participação foi assumindo distintos matizes em relação à amplitude ou restrição de seus alcances e implicações". No entanto, admitem a existência de um absoluto consenso em relação a uma definição genérica, segundo a qual participação seria "a capacidade que têm os indivíduos de intervir na tomada de decisões em todos aqueles aspectos de sua vida cotidiana que os afetam e envolvem ${ }^{4}$ ".

Além de reforçarem a idéia de que o conceito de participação se dilui em teorias diversas, os dois trabalhos citados compartilham uma visão que importa sublinhar: a de que a discussão sobre o tema é nova nas agendas pública e acadêmica.

\footnotetext{
of Pluralist Democracy (Yale U niversity Press, 1982); Lindblom, C. Política e Mercados (Zahar, Rio de Janeiro, 1979); Manley, J. "Neo-pluralism: a Class Analysis of Pluralism I and Pluralism II" (in The American Political Science Review, vol 77, jun 1983); Lindblom, C. "Comment on Manley (in The American Political Science Review, vol 77, jun 1983); Dahl, R. "Comment on M anley (in The American Political Science Review , vol 77, jun 1983).

4 Gascón, TAmargo ; Carles (2005) citam como autores cujas definições se aproximam dessa concepção Blas Tomic, García Delgado, Marshal Wolfe, Emanuel de Kart, Albert Meister, e organismos como a CEPAL e as N ações U nidas. Grifos ausentes no original.
} 
0 presente texto expõe dois conjuntos de argumentos relacionados a uma possível dimensão inovadora da participação. São eles a "idade" (ou antiguidade) do conceito de participação e a novidade que o uso recente e recorrente do conceito encerra. Sintética e simplificadamente, tais argumentos podem ser apresentados da seguinte forma: a) o conceito de participação tem a idade da teoria social moderna - algo em torno de quatro séculos -, como participação na pólis e, pois, participação política; b) a novidade introduzida pelo "debate teórico e político" no século XX consistiu em substituir 0 adjetivo política pelo adjetivo social, passando-se a empregar como sinônimas as expressões participação social e participação política; c) todavia, o uso clássico do conceito de participação como participação política difere do uso novo do conceito de participação como participação social porque o primeiro se refere à participação de todos os membros da pólis - condição de direito (ou de dever) universal -, enquanto que o segundo se aplica a segmentos específicos da população: os pobres, os excluídos, as minorias.

É possível perceber a emergência do conceito clássico de participação em associação com o que SAntos (1993) denominou o projeto sociocultural da modernidade iniciado no século XVI. Por "projeto sociocultural da modernidade", SANTos (1993) entende o paradigma de reflexão que passa a nortear as controvérsias desenvolvidas para explicar "cientificamente" a ordem social. Vale a citação do autor.

O projeto sócio-cultural da modernidade (se) assenta em dois pilares, o pilar da regulação e o pilar da emancipação. (...) O pilar da regulação é constituído pelo princípio do Estado, cuja articulação se deve principalmente a Hobbes; pelo princípio do mercado, dominante sobretudo na obra de Locke; e pelo princípio da comunidade, cuja formulação domina toda a filosofia política de Rousseau. Por sua vez, o pilar da eman- 
cipação é constituído por três lógicas de racionalidade: a racionalidade estético-expressiva, da arte e da literatura; a racionalidade moral-prática da ética e do direito; e a racionalidade cognitivo-instrumental da ciência e da técnica (Santos, 1993, 183).

Como o tema da participação aparece nesse "projeto"? O s pilares da regulação e da emancipação podem ser traduzidos como os eixos presentes na Filosofia política ocidental desde M aquiavel: a busca de uma explicação laica para o funcionamento da ordem social - pensada esta como um conjunto de indivíduos movidos por interesses auto-referenciados e diferentes, cuja convivência implica regulação -, e a construção de uma base cognitiva consistente para definir o próprio indivíduo, um ser racional, dotado de livre-arbítrio e dono de si mesmo, ao qual será acenada a utopia da emancipação (individual ou coletiva).

É com os contratualistas que o tema da participação emerge claramente. Em particular na obra de Thomas Hobbes, Leviatã, na qual, a criação da sociedade, política por excelência, se deve ao pacto que todos os indivíduos, naturalmente iguais, racionais e possessivos, fazem entre si. A pólis, a commonwealth (na redação de Hobbes), ou seja, o Estado-nação, o ente regulador, é uma invenção dos seres humanos, de todos os seres humanos. Todos participam da criação do Estado e, por isso, são não só legítima e igualmente partes da pólis como legítima e igualmente subordinados às regras que emanam do Estado. A obediência civil de todos, legítima porque todos tomaram parte na sua invenção, oferece a segurança necessária para que os indivíduos se dediquem desigualmente a seus labores privados.

A lógica da distinção entre uma esfera pública, inventada por todose na qual todos são igualmente cidadãos, e uma esfera privada, domínio dos diferentes interesses que os indivíduos proprietários de si mesmos portam, torna-se mais evidente nas formulações de John Locke, sobretudo nas que ele tece no Segundo Tratado de Governo. O s indivíduos, livres e iguais por 
natureza, criam, por acordo, a sociedade política ou civil (título do capítulo VII da citada obra), uma invenção humana inteiramente diversa da "sociedade conjugal" ou de qualquer outra forma de interação social que homens e mulheres naturalmente realizam. 0 Estado nacional é o artifício construído pelos indivíduos para concretizar o descolamento entre a esfera da igualdade (todos são membros da sociedade política) e o mundo da liberdade (onde cada um goza, a seu modo, o direito natural à propriedade).

Essa distinção público-privado, enunciada com precisão por Locke, mas já presente nos textos de Maquiavel e Hobbes, vai fundamentar as reflexões posteriores sobre o tema da participação. 0 argumento merece aprofundamento, sem dúvida, mas está aqui simplificadamente exposto para sublinhar a natureza política e igualitária que reveste a noção em seu tratamento originário. Participar é tomar parte na criação da própria pólis e, portanto, ser parte, em condições de igualdade, da mesma ${ }^{5}$.

Locke, no século XVII, Montesquieu no seguinte e Stuart Mill já no século XIX, são exemplares da trajetória da reflexão (que se pode chamar imprecisamente de liberal) sobre o tema da participação. N o primeiro, tanto a questão da separação de poderes - sobretudo a separação entre os poderes Executivo e Legislativo -, depois retomada com vigor por Montesquieu, quanto a questão da dimensão representativa do poder exercido no âmbito do Estado são contempladas de forma inter-relacionada. Não custa lembrar que o pacto imaginado por Locke, bem diverso daquele que Hobbes formula, é renovável, e a renovação se substantiva na escolha de "representantes" para o exercício do Poder Legislativo, ainda que "eleições" não precisem, para ele, ter regularidade previamente fixada.

Mas é na obra de Stuart M ill, Considerações sobre o Governo Representativo, que essas questões, bem como a relação entre elas, ganha notória

50 que também revela o caráter abstrato, principista, dessa igualdade. Locke tem absoluta consciência desse caráter, como demonstra no cap. VI do Segundo Tratado de Governo. 
visibilidade. Argumentador efusivo em prol da democracia representativa e ardoroso defensor da fórmula cada um, um voto (inclusive para as mulheres), enuncia as razões que fazem do governo representativo a forma ideal de governo: freio do despotismo, garantia de que "cada um é o único guardião seguro de seus próprios direitos e interesses" e, principalmente, força impulsionadora do desenvolvimento individual. Ao mesmo tempo, defronta-se com os dilemas que, à sua época, a ampliação da participação (política) colocava. Com efeito, na Inglaterra do século XIX, o alargamento das bases sociais do sistema político está em curso. As grandes reformas eleitorais de 1832, 1867 e 1884 universalizam o direito do voto para a população masculina, aumentando também a representatividade na tradução dos resultados eleitorais em cadeiras no Parlamento (Balbachevsky, 2005).

A partir de todas essas considerações, torna-se evidente que o único governo que pode satisfazer plenamente todas as exigências do Estado social é aquele no qual todo o povo participa; que toda a participação, mesmo na menor das funções públicas, é útil; que a participação deverá ser, em toda parte, tão ampla quanto o permitir o grau de desenvolvimento da comunidade; e que não se pode, em última instância, aspirar por nada menor do que a admissão de todos a uma parte do poder soberano do Estado. Mas como, nas comunidades que excedem as proporções de um pequeno vilarejo, é impossível a participação pessoal de todos, a não ser numa parcela muito pequena dosnegócios públicos, o tipo ideal de um governo perfeito só pode ser o representativo (MILL, 2005, 223)

Para Balbachevsky (2005), "a obra de Mill pode ser tomada como um compromisso entre o pensamento liberal e os ideais democráticos do sécuIo XIX". O fundamento desse compromisso estaria no "reconhecimento de que a participação política não é e não pode ser encarada como um privi- 
légio de poucos". A preocupação de Mill em dotar o Estado liberal de mecanismos capazes de institucionalizar esta participação ampliada, recorrente nos vários artigos que publicou (M ACPHERSON, 1977), ancorava-se na "aceitação de que, nas condições modernas, o trato da coisa pública diz respeito a todos" (BALBACHEVSKY, 2005, 195).

Stuart Mill procura compatibilizar os pilares do "projeto da modernidade" referido por SANTOS (1993) e por ele percebido como vítima de uma "contradição insolúvel presente desde seus alvores no século XVI." Contradição expressa justamente na impossibilidade não só de conciliar os dois pilares um com o outro, como de vincular ambos "à concretização de objetivos práticos de racionalização global da vida coletiva e da vida individual". A estratégia conciliatória de M ill passa pela participação (política e igualitária), ideal cuja consecução demandava ajustes civilizatórios e que permitiria "o movimento harmonioso de valores tendencialmente contraditórios, da justiça e da autonomia, da solidariedade e da identidade, da emancipação e da subjetividade, da igualdade e da liberdade" (SAntos, 1993, 183-184).

Participação é, assim, um conceito que vai, a partir do século XIX, abrigar-se sob as teorias da democracia liberal ou sob os diferentes "modelos" de democracia. Vai ainda se traduzir prioritariamente como voto, nos entes que representam a sociedade no interior do Estado e sempre como direito universal - ou que demanda universalização - de tomar parte nas decisões que afetam o coletivo, vale dizer, como participação política ${ }^{6}$.

Associado às interpretações (diversas) do desempenho da democracia, que, como regime político se instala de forma também variada no $O$ cidente, o conceito de participação adentra os anos novecentos. Nas

6 A inflexão que Marx imprime no pensamento ocidental, deslocando o eixo da participação política da esfera institucional para o campo da ação revolucionária, extremamente relevante para a composição de um painel das reflexões sobre o tema, não é abordada no presente texto. 
primeiras décadas do século XX, esbarra no pessimismo de "alguns dos melhores cérebros de então" (LESSA, Folha de São Paulo, 1997) - Vilfrido Pareto, Gaetano M osca, Robert M ichels (os chamados "elitistas"), Sigmund Freud, Max Weber (não etiquetados por nenhum rótulo, mas igualmente tidos como desencantados com as possibilidades de felicidade pública). M as, mesmo em sua versão negativa ou desencantada (a não-participação ou a baixa participação), o conceito de participação permanece central nas formulações que descrevem a impotência do cidadão para decidir a respeito de assuntos públicos, bem como sua diluição nas malhas da impessoalidade e da multidão.

Schumpeter, no final dos anos 30 (a sugestão interpretativa é também de LESSA, 1997), resgata o conceito de participação associado ao de democracia representativa, embora às custas de esvaziá-lo de qualquer encanto. Democracia é, para ele, um procedimento que funciona, na arena política, de modo análogo à concorrência no mercado. Dá aos indivíduos a oportunidade de participar, inserindo no universo político as incertezas que animam o mundo da economia - donde, a busca incessante por votos $^{7}$. A visão desencantada de Schumpeter certamente influenciou uma vasta produção acadêmica americana (sempre propensa à etnocentria) sobre (baixa) participação eleitoral, apatia política, idiotia das massas, etc.

Afastando-se, tanto do idealismo progressivista com que os liberais do século XIX conceberam a relação entre participação e democracia, quanto do procedimentalismo que caracterizou as investigações na linha schumpeteriana, Robert Dahl, um pluralista por convicção, revitaliza o conceito de participação no âmbito da ciência política. Desde o Prefácio à Teoria Democrática, de 1956, Dahl começa a elaborar a distinção entre democracia como valor - ou como ideal regulatório compatível com a

7 Joseph Schumpeter, Capitalismo, Socialismo e Democracia, Zahar, Rio de Janeiro, 1984, especialmente capítulos XX, XXI e XXII. 
emancipação, para manter o referencial do projeto de modernidade enunciado por SANTOS (1993) - e democracia como realidade, discernível em graus diferentes nos diferentes sistemas políticos democráticos espalhados pelo mundo. Esta distinção fundamenta sua obra mais difundida, Poliarquia, de 1970.

Enquanto valor, a democracia escapa dos rigores de uma conceituação científica, e, por isso, D ahl consigna o termo 'poliarquia' para indicar o arranjo institucional que permite abrigar formas de expressão dos conflitos sociais, oferecendo garantias para todos os envolvidos. Democratização é, para Dahl, um processo de progressiva ampliação da competição e da participação política. A dimensão da contestação é analisada como a ampliação da competição política, expressa na redução das barreiras institucionais à formação de partidos e outras associações, na regularização dos prazos para realização de eleições, na multiplicação dos cargos públicos ocupados pela escolha eleitoral, enfim, nas inúmeras garantias formais que caracterizam o processo de liberalização da esfera pública. Sistemas poliárquicos são aqueles que, uma vez liberalizados, ou seja, uma vez fixadas e reconhecidas as regras universais do jogo político, passam a incluir mais e mais parcelas da população. A participação, variável-chave no modelo dahlsiano, vindo em seqüência à liberalização, assume o caráter de direito universal dos cidadãos à manifestação de suas preferências em termos de ações governamentais.

Como se vê, em reforço ao que já foi assinalado acima, o conceito de participação tem um percurso, nas ciências sociais, marcadamente ligado às teorizações sobre a democracia, com o que, mais uma vez, revela seus traços essenciais: é um dote (trasladado em direito ou em dever) universal, que se exerce na esfera pública, prioritariamente através do voto creditado às instâncias de representação política.

O utrossim, mesmo nas concepções que se afastam ou não enfatizam a via da representação para a realização da democracia, o princípio da universalidade se revela fundante e recorrente. Tanto quanto se revela 
precípua a dimensão política da ação participativa. A prática política constante é requisito para preservação da liberdade e, pois, para a vigência da democracia. Como observa Q UIRINo (2005):

Para Tocqueville, embora seja necessário que se anuncie a liberdade como um direito, que se formalize ou institucionalize através de leis e instituições, essasmedidas sozinhas não seriam suficientes para que se garantisse a liberdade. Isso porque o verdadeiro sustentáculo da liberdade está posto na ação política dos cidadãos e na sua participação nos negócios públicos. 0 que pode, evidentemente, ser incentivado através da implantação de instituições tais como a descentralização administrativa, a organização de associações políticas que tenham como finalidade a defesa da cidadania ou mesmo a existência de grandes partidos. Enfim, é sem dúvida de máxima importância que se possa criar e desenvolver organizações livres que garantam a manutenção do espaço da palavra e da ação (Q UIRINo, 2005, 157).

Rousseau talvez seja o mais emblemático dos clássicos no que concerne ao tema da participação. Tido como avesso ao formato representativo do sistema político, ele entrou para a história do pensamento político como o grande teórico moderno da democracia direta. Ao identificar as facções como impeditivas à manifestação da vontade geral ${ }^{8} \mathrm{e}$ ao denunciar a grande propriedade como origem da opressão ${ }^{9}$, tornou-se uma espécie de paladino póstumo da Revolução Francesa.

A democracia (ou a comunidade política justa e legítima) para Rousseau, exige participação. Não apenas a participação de todos na sua

8 Rousseau, Do Contrato Social, livro II, cap. III.

9 Rousseau, Discurso sobre a origem e osfundamentos da desigualdade entre os homens[1755]. 
criação - esta também ${ }^{10}$ - mas a reiteração permanente da vontade geral que igualmente emerge do ato fundante. Rousseau não execra a representação parlamentar como mecanismo já então consagrado para reduzir o absolutismo monárquico. Vai, antes, propor formas de subordiná-la, tanto quanto o aparato administrativo do Estado, à soberania do povo. A cidadania como a face pública do indivíduo e o poder soberano como atributo dos cidadãos (e só deles) constituem os fundamentos para repensar os papéis da representação e da participação.

O s deputados ou representantes (capítulo XV, livro III, do Contrato) não representam a vontade geral, pois não há como fazê-lo - não se representa uma vontade. Como os governantes (príncipes ou magistrados), constituem servidores do soberano. São intermediários que recebem do soberano as ordens que darão ao povo para que o Estado permaneça em bom equilíbrio.

Participação - política e igualitária - e não somente mediante o voto, é o instrumento de poder que o povo possui. Se dele abdica, torna-se escravo e joga o Estado (a Pátria, como Rousseau várias vezes designa o ente coletivo), na ruína. Preferir a bolsa ao serviço público, deixar de cumprir os deveres cívicos, despreocupar-se dos negócios do Estado - eis as fontes de perdição da cidadania. O ceticismo de Rousseau quanto a possíveis transformações da sociedade européia no século XVIII não inibe sua retórica de utópico moderno, conclamando o povo a participar.

Não tendo, o soberano, outra força além do poder legislativo, só age por meio das leis e, não sendo estas, senão atos autênticos da vontade geral, o soberano só poderia agir quando o povo estivesse reunido. 0 povo

10 Como os demais contratualistas, Rousseau trabalha com a construção abstrata do pacto fundante. Mas diversamente de $\mathrm{H}$ obbes, para quem o pacto cria um ente inexistente antes, 0 Estado, e também de Locke, cujo pacto institui os poderes de governo, o pacto fundante de Rousseau é o ato pelo qual um povo é povo (Do Contrato Social, Livro I, cap. V). 
reunido - dir-se-á - que quimera! Hoje é uma quimera, mas não o foi há dois mil anos. O s homens mudaram de natureza? (RO USSEAU, 2005, 234).

O povo reunido, como corpo coletivo, participando ativamente dos negócios públicos, manifestando a vontade geral em praça pública: esta imagem utópica traduz a essência do "princípio de comunidade" referido por Santos (1993) como a contribuição de Rousseau ao projeto da modernidade. Em outras palavras, trata-se do princípio republicano da virtude cívica que redimensiona a noção de participação política igualitária, transmutando o voto de cada um em voz de todos os cidadãos. Os revolucionários de 1789, protagonistas notórios do projeto de modernidade, não tiveram dúvidas em brandir o Contrato como bandeira.

É justamente a este argumento - a força do ideário republicano de inspiração rousseauniana na França - que Donzelot ; EPSTEIn (2006) recorrem para explicar as baixas taxas de participação da população francesa em projetos recentes de políticas públicas. O s autores examinaram a implementação de programas de restauração urbana em quatro cidades francesas, interrogando os encarregados das operações de demolição e reconstrução, com o intuito de recolher elementos para classificar a participação da população prevista nas experiências. Utilizando a escala de Sherry Arnstein, uma metodologia criada em 1969, nos Estados U nidos, para medir "participação11", concluem que em nenhuma das experiências a participação ultrapassa o segundo nível da escala de Arnstein (participação simbólica). Apresentam, em seguida, experiências participativas de

11 Arnstein elaborou uma hierarquia de práticas participativas, distinguindo três níveis e oito graus possíveis na escala de participação. No nível mais baixo (nível 1) não há participação, há manipulação ou terapia (a participação visaria apenas obter apoio do público, mediante publicidade). O segundo nível é de cooperação simbólica: os "participantes" são informados, consultados ou "apaziguados". 0 nível 3 representa "poder efetivo dos cidadãos", mediante parceria, delegação de poderes e, ponto culminante, controle cidadão. 
remodelação urbana colocadas em prática nos Estados U nidos e na GrãBretanha, que evidenciam a concretização do "poder efetivo dos cidadãos" (o nível 3 da escala de Arnstein). A resposta para o porquê, na França, a participação "é um exercício mais encantatório do que efetivo, enquanto nos países anglo-saxões indica um imperativo pragmático", está no fato de que, na França, a noção que norteia a ação pública reside no conceito de interesse geral, ao passo que os anglo-saxões têm como referência o bem comum (DONZELOT ; EPSTEIN, 2006).

0 interesse geral, seguem os autores, constitui, na França, uma espécie de substituto contemporâneo do conceito rousseauniano de vontade geral. A participação é pouco efetiva na França, explicam, porque os indivíduos que se dispõem a participar pontualmente de programas sociais (mas não se interessam em participar das esferas políticas estabelecidas) são percebidos e denunciados como defensores de seus interesses privados, em contraposição ao interesse geral encarnado pelos poderes públicos. 0 conceito de participação, todavia, continua sendo cultuado pelos franceses " porque remete ao sonho de obter uma confirmação unânime da decisão política pelo cidadão que, ao participar, abandona seus interesses privados agindo conforme a verdadeira legitimidade de uma vontade geral de facto"12 (D onzelot ; Epstein, 2006, 33).

Bem-comum (a common wealth de Hobbes) é um conceito que se distingue do interesse geral em dois pontos. Primeiramente porque o bem comum, ao invés de se opor aos interesses particulares, procura uni-los, visa estabelecer um consenso, um critério de acordo. Em segundo lugar, a noção de bem comum não envolve nenhuma intenção de alcançar um plano de igualdade real entre os atores sociais; ao contrário, nela está implícito o reconhecimento de que há diferenças substantivas entre aqueles que têm os meios de decidir (o poder, o dinheiro) e aqueles que são

12 Donzelot ; Epstein, op. cit.. Julia Polessa, da equipe do LEPS, fez a tradução. 
afetados pela ação projetada (os stakeholders). 0 que se coloca em pauta, indicam Donzelot ; EPSTEIN, é a realização de um acordo.

Os autores terminam o artigo afirmando que os franceses "buscam na participação muito mais uma legitimação da decisão do que uma mobilização pela ação" (Donzelot ; Epsteln, 2006, 34). A democracia participativa na França tem o sentido de associar os cidadãos à tomada de decisões, "tendo como pano de fundo a tradição rousseauniana do Contrato Social" (D onzelot ; Epstein, 2006, 34).

Este tipo de participação que os franceses rejeitam e que encontra recepção favorável entre ingleses e americanos, não é exatamente a participação tal como a ciência social - de Hobbes a Dahl, pelo menos - compreendeu. Não é mais o conceito que, utilizado de modo variado por diversas teorias formuladas desde o século XVI, guardou como marca comum de seu emprego, a designação de um processo político e universal.

A novidade da discussão atual sobre participação consiste no entendimento de que participar é intervir na tomada de decisões "em todos aqueles aspectos da vida cotidiana" que afetam os indivíduos (GAscón, TAMARGO ; CARLES, 2005, 2). O u seja, não mais apenas intervir na dimensão pública da política, mas, sobretudo, intervir nas decisões que concernem à vida privada dos indivíduos: onde morar, como preservar a saúde, em que ofício trabalhar, etc. O ra, não são todos os indivíduos que precisam ter incrementada sua capacidade de intervir nas decisões que afetam sua vida cotidiana. Todos podem escolher representantes para o Parlamento, votar para a Presidência da República ou manifestar sua vontade em referendos ou plebiscitos. $\mathrm{Nem}$ todos podem, igualitariamente, preferir tal ou qual bairro para moradia, optar por determinado tipo de tratamento médico ou decidir seu futuro profissional.

Não por acaso, a participação discutida na literatura examinada a seguir é qualificada como participação social. Trata-se de um mecanismo propositalmente destinado a incluir segmentos que, na esfera da socieda- 
de (ou do mercado), em sua vida cotidiana, encontram-se excluídos de oportunidades de escolha.

É claro que a nova conceituação de participação - participação social - não dá as costas, malcriadamente, à dimensão política. De todo modo, trata-se de intervir em processos decisórios que atingem o coletivo. Muito menos é unívoca. Conforme observam os autores que se vêm dedicando a examinar o estado das artes no que respeita ao tema, em momentos e contextos históricos diversos ao longo da segunda metade do século XX, diferentes maneiras de "definir" participação se sucederam. A novidade, no entanto, parece ter maiores dificuldades que sua antecessora, a participação política tout court, de encontrar um marco teórico no qual se abrigar.

Dois fatores assinalados por CORTES se mostram esclarecedores da "criação de novas formas de envolvimento dos cidadãos no processo político". O primeiro seria a "tangível desilusão com as instituições políticas, verificada em várias democracias liberais ocidentais, desde o final dos anos sessenta" (CoRTES, 1996a, 31). Declinante participação pela via do voto, redução da confiança na representação parlamentar, afastamento dospartidos políticos de suas identidades programáticas e outros desencantos tornaram-se objetos de inúmeros estudos, assim como o crescente controle das corporações de negócios sobre a competição partidária, a influência dos arranjos corporativistas e o caráter cada vez mais tecnocrático das decisões em políticas públicas. Por outro lado, a autora vê nos novos movimentos sociais que se avolumam ao final dos anos sessenta e durante os anos setenta, um fator também atuante na inflexão ocorrida ${ }^{13}$.

A novidade, ou seja, a compreensão (militante e teórica) da participação como participação social, conseqüência do "clima de desilusão com os mecanismos participatórios tradicionais das democracias liberais e [da]

13 Entre esses novos movimentos estariam Maio de 68 (em Paris), as organizações de moradores, ecológicas e de consumidores nos EUA, em países europeus e latino-americanos (Co RTES, 1996b). Mais recente, o Fórum Social M undial poderia ser incluído como espaço de convergência desses movimentos. 
emergência de novos grupos de interesse" (CO RTES, 1996a, 31), fundamenta-se, como percebe a autora, no princípio (ou no valor) da autonomia da organização societária ante as instituições que conformam o establishment político. No caso da América Latina, tal princípio (ou valor) teria sido reforçado naquele momento histórico, tanto pela expansão de movimentos emancipatórios em prol de "mudanças radicais no sistema político e econômico" (Gascón, Tamargo ; Carles, 2005, 3), nos anos 60 principalmente, quanto pela inevitável identificação entre o establishment político e as ditaduras que ali permaneceram instaladas nas duas décadas subseqüentes ${ }^{14}$.

O ra, os movimentos emancipatórios na América Latina dos anos 60 no Brasil, antes de 64, em alguns países adentrando os 70 - tinham como objetivo geral a incorporação das massas, dos oprimidos, dos explorados, dos trabalhadores e camponeses, etc., ao cenário político e ao mundo da vida "civilizada". A mobilização de tais setores, através de sindicatos, associaçõese partidos era tida como crucial para que pudessem vir a participar efetivamente da transformação que se julgava próxima (GASCón, TAMARGo ; CARLES, 2005).

O utrossim, a pugna pela democratização - no Brasil, como em outros países da América Latina, em linha ascendente nos anos 80 - vai articular nitidamente a derrogação da institucionalidade autoritária à questão social. A articulação se revela, sobretudo, nas denúncias do caráter centralizador e burocrático do processo decisório concernente à política social e, conseqüentemente, no aceno das bandeiras alternativas da descentralização e da participação. Até porque, como foi quase que exaustivamente demonstrado pela literatura sobre processos decisórios sob o autoritarismo, as elites econômicas participavam, por vias informais e formais, das decisões então tomadas ${ }^{15}$. Consequentemente, o imperativo da

14 É também como afirmação desse princípio (ou valor) que Fernandes (1994) explica o aparecimento das O NGs no Brasil na década de 70, em pleno autoritarismo militar.

15 Ver VIANNA (1987). N este livro, encontra-se uma resenha da bibliografia sobre a representação de setores economicamente dominantes em espaços de decisão no interior do Executivo durante o período autoritário. 
participação não se dirigia a toda a sociedade e sim, àqueles segmentos social e economicamente alijados. Essa foi a natureza da participação reivindicada então, na área de saúde.

CORTES menciona ainda um terceiro fator atuante no "remodelamento das organizações políticas das democracias liberais", elucidativo também da recente inflexão sofrida pelo conceito de participação: a reforma do Estado (Co RTES, 1996a, 31). M udanças promovidas por vários Governos nas estruturas burocráticas estatais, em função do contexto econômico internacional que emerge na segunda metade da década de 70, implicaram a delegação de funções à sociedade (e ao mercado), bem como a criação de mecanismos participatórios destinados a desburocratizar - melhor seria dizer domesticar - os processos decisórios. Essa vertente da participação, social, passou a merecer a atenção dos formuladores de políticas, e dos formuladores de teorias ao longo dos anos 90 . Formuladores de políticas, situados em diferentes posições do espectro político e formuladores de teorias, adeptos de diferentes matizes ideológicos no interior das ciências sociais, vêm dedicando-se, desde então, a exaltar ou explicar a novidade. U m aparente consenso se constituiu em torno do tema participação, cada vez mais societalizado e cada vez menos politizado. Ao seu encontro acorrem conceitos díspares como capital social, empoderamento, responsabilidade social das empresas, gestão corporativa, terceiro setor, governança, conceitos estes que se originam, tanto de "novos campos" da ciência social - a sócio-economia, por exemplo -, ou da "descoberta de novas realidades" que se apresentam ao cientista social, quanto das modernas técnicas de administração.

O desvendamento deste aparente consenso se configura um desafio não desprezível para os cientistas sociais contemporâneos. Em particular para aqueles que, por opção teórica e ideológica - sempre vale frisar que teoria e ideologia formam um par briguento, mas inseparável nas ciências sociais -, dedicam-se a analisar a democratização das políticas públicas na área de saúde. 


\section{A reflexão acadêmica sobre a participação da sociedade no sistema de saúde brasileiro: uma sistematização em curso}

No intuito de mapear a produção acadêmica recente no Brasil sobre o tema da participação em saúde, procedeu-se a uma investigação exploratória de periódicos a partir da lista $Q$ ualis ${ }^{16}$ de publicações do portal CAPES, disponível na internet. Foram selecionados os periódicos A, B e C, brasileiros, de circulação local, nacional e internacional, relacionados à área de saúde coletiva. Considerando a Constituição Federal de 88 um marco na institucionalização da participação social na área da saúde, a busca bibliográfica abrangeu o intervalo de janeiro de 1988 a agosto de $2005^{17}$.

0 resultado da análise exploratória foi a localização de 99 artigos científicos, classificados basicamente em estudos de caso (59\%) e estudos teórico-reflexivos (41\%). Talvez por ser este um tema atraente, fecundo e capaz de gerar posicionamentos polares e entusiasmados, a expressiva maioria dos autores é ou foi militante na questão.

Q uanto à década de publicação dos artigos, apenas $2 \%$ são anteriores a 1990; 54\% concentram-se na década de 1990 e 44\% foram publicados entre 2000 e 2005. 0 número próximo de artigos publicados ao longo da década de 1990 e na primeira metade da década de 2000 sugere 0 quanto o tema está em voga no meio acadêmico.

16 Q ualis é o resultado da classificação feita pela CAPES dos veículos utilizados pelos programas de pós-graduação para divulgação da produção intelectual de seus docentes e alunos. Esta base de dados constitui importante fonte de informação para as diferentes áreas do conhecimento. A classificação é feita ou coordenada pelo representante de cada área e passa por processo anual de atualização. Os veículos de divulgação citados pelos programas de pósgraduação são enquadrados em categorias indicativas da qualidade - A, B ou C e do âmbito de circulação dos mesmos - local, nacional ou internacional. As combinações dessas categorias compõem nove alternativas indicativas da importância do veículo utilizado, e, por inferência, do próprio trabalho divulgado (CAPES, 2005).

170 levantamento contempla também teses de doutorado e dissertações de mestrado nas áreas de Saúde Coletiva e Ciências Sociais. Na busca, foram identificadas cerca de 230 teses e dissertações que não são aqui examinadas. 
De 57 artigos que explicitam a região brasileira onde foram realizados os estudos, $57,9 \%$ são do sudeste, seguidos por $19,3 \%$ do nordeste, $10,5 \%$ são de âmbito nacional, 10,5\% referem-se ao sul e, finalmente, $1,8 \%$ ao centro-oeste.

A participação social em saúde é tratada de diversas formas nos artigos investigados. Verificam-se abordagens do tipo das adjetivadas por Co RTES (2005) como céticas ou como esperançosas, além das que pontuam limites e possibilidades da participação da sociedade nas políticas públicas da saúde. Neste sentido, a análise preliminar dos 99 artigos levantados, com base nos resumos, mostra que, em $56,6 \%$ os autores expressam uma posição claramente favorável à participação social na saúde. Em 23,2\%, a manifestação das críticas supera os aspectos positivos da participação, reforçando a pertinência deste debate na área da saúde coletiva; $6 \%$ dos resumos apresentam um equilíbrio na avaliação dos limites e das possibilidades da participação e, em $14,1 \%$ não foi possível identificar uma tendência ou ponto de vista predominante. Finalizados o levantamento e a classificação preliminar, iniciou-se a leitura e os fichamentos das 99 publicações, já tendo sido fichados 33 artigos.

De modo geral, os autores que estudam a participação na área da saúde designam como participação a capacidade de os indivíduos influenciarem as decisões políticas que dizem respeito à sociedade em que vivem (Gascón, TAmargo ; Carles (2005); Cortes, 1998a). A participação aparece nestes estudos como um valor em si, isto é, participar independentemente dos resultados imediatos é algo intrinsecamente positivo. Nesta perspectiva, considera-se a participação, em suas diversas formas ou graus de envolvimento, um estímulo à ampliação da cidadania, por fomentar o capital social e contribuir para o empoderamento dos participantes. É possível afirmar que, com maior ou menor intensidade, esta visão perpassa todos os estudos sobre participação no campo da saúde coletiva, pois as 
demais dimensões da participação vinculam-se a ela. Assim, a ampliação da cidadania é tomada como um dos argumentos que, em última instância, justifica e atribui sentido à participação da sociedade na área da saúde (LABra; Figueiredo, 2002)18.

0 segundo aspecto que se evidencia nos artigos em tela diz respeito ao caráter político da participação como meio de democratização do Estado e da sociedade. N os trabalhos que enfocam a questão, a ênfase recai sobre a possibilidade de a participação política/social influenciar o desenho e os encaminhamentos das políticas de saúde nas diferentes instâncias da Federação (CoRTES, 2002 e 1996a; GERSCHMAN, 2004). U m contingente significativo de estudos concebe a atuação nos espaços de participação voltada para a qualificação da gestão, a maior eqüidade na distribuição dos recursos, o acesso aos serviços e a melhora da atenção à saúde. Em tais abordagens, participação constitui um elemento da 'boa' governança ${ }^{19}$.

U ma terceira perspectiva, mais instrumental, adepta da participação comunitária e do auto-cuidado, deriva da concepção americana de medicina comunitária em que os indivíduos, as famílias e a comunidade dividem com o Estado a responsabilidade pela atenção e pela condição de saúde da população (Cortes, 1996a; Carvalho, 1995). Difundiu-se a partir de recomendações das agências internacionais de desenvolvimento, tais como a Declaração dos Cuidados Primários de Saúde, resultante da Conferência de Alma Ata promovida pela U NICEF/O MS em 1978 (CoRTES, 1996a).

O s conselhos de saúde brasileiros estão mais próximos dos mecanismos participativos criados com o intuito de fortalecer a democratização do Estado ante a crise de legitimidade das formas tradicionais de represen-

18 N ote-se que esta ampliação da cidadania é entendida como extensão da mesma aos setores marginalizados.

19 Segundo SANTOS, governança "se refere às capacidades gerenciais dos governos, à eficácia de suas políticase ao processo decisório envolvido na promoção de desenvolvimento socioeconômico sustentável, em contextos democráticos" (SANTOS, apud Co RTES, 2005, 5). 
tação de interesses nas democracias liberais, do que com experiências participativas inspiradas na estratégia de cuidados primários de saúde (Co RTES, 1996a e 1998a). No entanto, chama atenção a identificação de 37 artigos pelo descritor participação comunitária, dos quais 22 enunciam nos resumos a discussão de aspectos relacionados ao auto-cuidado ${ }^{20}$.

Cabe destacar que, frequentemente, a delimitação entre as abordagens é tênue e os estudos abarcam mais de uma delas. As diversas dimensões da participação na área da saúde não são excludentes e, portanto, se mostram complementares. Dos 33 artigos fichados, 15 são estudos de caso e 18 são reflexivos. A maior parte deles aborda a participação com foco no Estado e na consolidação do SUS.

Interpretação recorrente é a de que, apesar de não garantir, por si só, a participação plena e efetiva, inicialmente idealizada pelo movimento da Reforma Sanitária, a definição legal da participação social via conselhos e conferências de saúde representa uma conquista na construção da cidadania (O 'D wyer ; Moysés, 1998; GonçAlves ; Almeida, 2002), um "processo políticopedagógico (...) de fortalecimento da sociedade civil" (SILVA, Egydıo ; SouzA, 1999 , 40). Em concordância com esta avaliação, consideram-se os conselhos de saúde espaços nos quais há "possibilidade de transformação dos sujeitos sociais em sujeitos políticos" (VANDERLEl ; WIT, 2003, 132). N esses espaços os sujeitos sociais poderiam exercer a cidadania, o poder atrelado ao ato de participar, constituindo-se em sujeitos políticos hábeis e potentes para induzir intervenções positivas na implementação do SU S (GonçALVES; ALm EIDA, 2002).

A população brasileira, segundo PEDRoSA (1996), não compreende saúde como um direito social, e identifica o setor por meio do consumo

20 Ivan Illich fornece elementos teóricos que justificam a crítica a visão instrumental da participação na saúde. Illich analisou o processo de medicalização da sociedade resultante da expansão da medicina como uma expropriação da vontade e da liberdade do sujeito em prol do dever e da tarefa (SouzA, 2004). Até o momento, não foram encontrados estudos sobre a participação na área da saúde com base neste referencial teórico. 
de serviços. Para este autor, a interlocução da sociedade com o Estado, concretizada por meio dos conselhos, permitiria que o papel do Estado fosse revisto, e qualificaria os indivíduos como cidadãos, com capacidades de interação que iriam além da fiscalização. Nesses espaços, os atores não estariam mais em lados opostos, o que favoreceria o contato com o discurso do outro, como a fala técnica, por exemplo, "podendo resultar (...) [na] formação da consciência sanitária”. (SILvA, Egydıo; SouzA, 1999:39-40).

COHN, ELIAS; JACOBI (1993) também procuram mostrar a potencialidade dos conselhos de saúde enquanto catalisadores do processo de educação para a cidadania e de promoção da consciência sanitária. Eles identificaram uma tendência dos representantes de usuários a complexificarem as questões de saúde, baseados na experiência da participação descentralizada. Nesse caso, a participação foi considerada sob o prisma de uma prática educativa, em que cada segmento do conselho aprendeu a ver 0 outro com suas carências, reivindicações e expectativas. Barros (1998) afirma, em linha semelhante, que

a burla dos dispositivos constitucionais só poderá ser impedida se houver um decisivo movimento social que opere como barreira política a esses desígnios. O sconselhos de saúde podem ser o espaço de disseminação de informações que alimentem a luta pela preservação do direito universal à saúde (BARROS, 1998, 19).

Essa ponderação é reiterada por CARVALHo, que acrescenta: os conseIhos surgiram para "dotar o Estado de ânimo institucional e estrutura organizacional para implementar as políticas sociais universalistas (...)" (CARVALHO, 1998, 23).

Já Valla (1998), embora sem abrir mão dos Conselhos M unicipais de Saúde, questiona a concepção de democracia representativa vigente nestes fóruns e sinaliza o risco de "encurralamento" dos movimentos populares nestes espaços. 
A lentidão em agir dos CM S e a sua grande dependência dos Secretários M unicipais de Saúde e dos componentes dos profissionais de saúde (gestores e funcionários), juntamente com os graves problemas de saúde que afligem a população brasileira, devem servir como um alerta para a retomada das experiências da democracia direta (VALLA, 1998, 32).

A discussão da participação social como componente essencial para a preservação do direito universal à saúde, construção da cidadania e fortalecimento da sociedade civil liga-se diretamente à concepção da participação como parte do processo de democratização do Estado. Esta vertente abriga o maior número de estudos analisados.

Pedrosa (1997) observou que os Conselheiros de Saúde, no Piauí, consideram que o controle social insere-se no plano da universalidade dos direitos sociais. Esta interpretação é complementada por Co STA; N O RONHA (2003) ao concluírem que o papel social dos conselhos é a promoção de justiça social e a melhoria do nível e situação de saúde da população representada nestes espaços. Eles citam Carvalho (1998), para quem a institucionalização da participação significa a inclusão de estruturas de representação direta da sociedade no Estado. Esta visão enfatiza o potencial dos Conselhos de Saúde para democratizar as decisões do setor, incorporando a sociedade. Para SILVA, os Conselhos de Saúde seriam ferramentas adequadas para "abrir os fechados círculos burocráticos de decisão (...) [e] incorporar a sociedade às decisões de forma indireta, mediante representantes de suas associações" "(SILVA, 2004, 132).

Para O 'Dwyer ; M oysés (1998) e CARVALHo (1998) os Conselhos são fatores integrantes do processo de democratização da sociedade e do Esta-

21 Por meio desses canais, demandas de grupos excluídos do poder e, conseqüentemente, dos processos decisórios passariam a ser formal e publicamente acolhidas. Embora os Conselhos colaborem para a "consolidação de formas mais democráticas de representação de interesses, eles têm seu funcionamento limitado e condicionado pela realidade concreta das instituiçõese da cultura política dos municípios brasileiros “(CORTES, 1998a, 10). 
do. Pessoto, Nascimento; Heimann complementam que "o poder dos conselhos não sub-roga o poder dos Executivos, nem dos Legislativos. Eles concebem, assim, a existência de outros centros de poder, tão legítimos e necessários quanto o centro do poder político de Estado". Concluem ser este um movimento necessário à implantação de uma sociedade "democrática pluralista, em que o poder autocrático é contrastado pelo poder ascendente, ao mesmo tempo em que o poder monocrático é confrontado pelos vários centros de poder emergentes e derivados da auto-organização da sociedade civil" (Pessoto, N Ascim ento; H eimann, 2001, 96). Costa ; N oronha entendem que a atuação recente dos Conselhos evidencia a aglutinação de "forças emergentes da sociedade e o questionamento da estrutura institucional, tecnocrática, centralizadora, autoritária e normativa do Estado brasileiro" (COSTA ; NoRonhA, 2003, 361).

Alguns autores defendem a atuação dos canais participativos como meio de consolidação do Sistema único de Saúde. ZANARDI ; CoRdonI JR (2004) descrevem a contribuição dos usuários na construção de um modelo de saúde. Cohn, Elias ; Jaco bi (1993), assim como Gonçalves ; Alm EIdA (2002) apontam o papel de fiscalização da sociedade sobre os Governos M unicipais, Prata et al. (2004) manifestam o desejo (mais que a evidência) de que, por meio da participação em canais institucionalizadose descentralizados, a comunidade possa avaliar os serviços prestados e o relacionamento dos profissionais com os usuários 22. D AL Poz ; Pinhelro (1998), porém, admitem que o controle dos serviços é tarefa complexa, pela diversidade de interesses envolvidos na composição dos conselhos, que explicitam uma relação desigual, principalmente em termos da linguagem técnica ${ }^{23}$.

220 controle social, por natureza, não tem comprometimento com partido político algum, 0 que o torna potente para fortalecer o SUS como uma política nacional (SILVA, 2004).

23 Para estes autores, a maioria dos representantes dos usuários não tem clareza sobre como avaliar a qualidade dos serviços de saúde. Controle e avaliação estão limitados pela "autonomia dos profissionais de saúde, sobretudo o médico, considerado pela sociedade como detentor do saber e da prática da cura e, na maior parte dos casos, presidente dos conselhos" (D AL Poz ; Pinheiro, 1998, 29). 
De 1989 a 1992, a participação popular foi incorporada a todos os níveis da Secretaria M unicipal de Saúde de São Paulo, com poder de decisão nas atividades de planejamento e organização, coordenação e gerenciamento dos programas desenvolvidos. Segundo CoHN, ELIAS ; JACOBI (1993) esta constitui uma possibilidade concreta de criação de condições para maior eqüidade na distribuição dos recursos, em face de sua escassez. 0 desafio estaria em formular mecanismos e canais institucionais capazes de garantir a transparência da Administração, encaminhar soluções das demandas e assegurar formas efetivas de participação em projetos inovadores.

Para Dal Poz ; PInheiro (1998), quanto mais avançada a condição de gestão municipal da saúde, melhores as condições para um Conselho M unicipal de Saúde (CMS) desempenhar suas atividades, tendo importância na condução da política local e contribuindo para a descentralização das ações de saúde. Também para CoRTES, os CMS passaram, a partir da segunda metade dos anos 1980, a ser "elementos-chave no contexto da descentralização" (Co RTES, 1998a, 12).

O direito dos cidadãos, ou pelo menos a potencialidade de integrarse ao processo de decisão política da saúde é o aspecto preponderante nos artigos. Todavia, influenciar ou tomar parte no processo de decisão de tal política setorial implica formular ou orientar projetos; definir prioridades; estabelecer contrapontos ao desenvolvimento das medidas tomadas; ler criticamente planos e relatórios; acompanhar balanços financeiros e orçamentários; envolver-se na administração dos serviços e sistemas de saúde. Tarefas, enfim, que requerem capacitação técnica e disponibilidade de tempo superiores às que a maioria da população possuii ${ }^{24}$. Restaria,

24 GonçALVES ; ALmeida constatam o problema em estudo de caso e consideram que o CM S não atua como instância real de decisão, "devido a pouca experiência no exercício da participação política em espaços concretos com poder de deliberação" (GonçAlves ; Alm EIDA, 2002, 171). 
pois, aos conselhos, o papel de espaços de diálogo, negociação, formação de consensos, troca de saberes e partilha de poder (Gonçalves ; Almeida, 2002; Wendhausen ; Caponi, 2002; Silva, Egydio; Souza, 1999).

\section{4. À guisa de conclusão}

É patente, entre os artigos examinados, uma visão de participação como participação social, nos moldes apontados na sessão inicial deste texto. Céticos ou esperançosos, mais, ou menos militantes, os autores citados compartilham a idéia de que a certas camadas da população é necessário garantir voz. Entretanto, de certo modo, confundindo inclusão com universalidade de direitos, deixam incólume a razão estrutural que impõe tal "necessidade" - necessidade que os conselhos municipais de saúde satisfariam -, qual seja, o fato de que outras camadas da população prescindem da voz porque dispõem do mecanismo de saída. A participação, bem como a descentralização, não garante que o SU S seja um sistema efetivamente universal, na medida em que os segmentos sociais dotados de alguma capacidade de pressão se exilam do sistema público, aderindo aos planos privados. Funcionando na realidade como um sistema para pobres, o SUS tem, de fato, seu caráter universal comprometido. E igualmente comprometida fica a participação nos conselhos que integram sua institucionalidade.

A participação "social" é, indubitavelmente, uma prática de cidadania. Para o cientista social, porém, não basta brandir bandeiras. Cabe conhecer a natureza e os limites dessa prática.

No caso da literatura tratada acima, duas lacunas ajudam a obscurecer tal conhecimento. A primeira é a contradição, não observada, entre a idéia de que a participação em si constitui um ganho democrático - e, portanto, é louvável que esteja legalmente estabelecida - e a forma pela qual ela se encontra formalizada na lei. Participação é ganho porque civi- 
liza (ou conscientiza, ou "empodera"), e neste sentido participar significa atuar diretamente, estar presente na ágora. Maso formato institucionalizado de tal participação nos Conselhos M unicipais de Saúde é representativo. Trata-se de um espaço de representação dos usuários e não, de uma arena de exercício da democracia direta.

A segunda lacuna se encontra no baixo reconhecimento da fluidez que a fronteira entre participação e delegação apresenta. Participar é (entendido como) tomar parte em decisões; decisões que envolvem tarefas que são precípuas a funcionários supostamente competentes (ou pagos) para realizá-las. A questão remete à complexidade técnica dessas decisões, e à concepção do papel que a participação deve desempenhar. Dar voz ao usuário pobre pode ser um substitutivo do atendimento que ele não tem.

Q uestões como estas estão na agenda. Inconclusas e instigantes, convidam pesquisadores interessados na área da saúde e em outras políticas sociais a aprofundarem o conhecimento sobre o tema da participação. Tanto a "velha" participação quanto a "nova" participação.

\section{Health participation: what are we talking about?}

\section{Abstract}

This article was prepared under the project Gestão Participativa em Saúde (participative health administration): a study and systematization of the academic production and the experiences with health councils and conferences developed in the Laboratório de Economia Política da Saúde (laboratory of political economy of health) at U FRJ (Federal U niversity of Rio de Janeiro). The author presents some thoughts on the status of the concept of participation in the field of social sciences, within a historical perspective, for the purpose of providing a background to enable a more accurate understanding of the recent and recurrent use of this concept, as well as its increased association with the field of health. These are temporary 
formulations presented in order to stimulate debate and contribute to clarify questions on the possibilities and limits of the instances of social control within Sistema Único de Saúde (SUS - unified health system). Then, the paper presents a preliminary review of articles in the field of Public Health, published in Brazil over the past two decades, concerning "social participation and health", i.e., works on the mechanisms of social participation in the health system, including the councils created (or institutionalized) as a result of the law 8142, in December 1990.

This article is a preliminary study, since it is a research in progress and because it presents considerations not fully developed in order to stimulate debate.

Keywords: Political participation. Social participation. Participation and health. Health councils.

\section{Referências}

BALBACHEVSKY, Elizabeth. Stuart M ill: Liberdade e Representação. In: W EFFO RT, Francisco C. (org). Os Clássicos da Política. Vol 2. São Paulo: Ática, 13a edição, 2005.

BARRO S, Elizabeth Diniz. Os Conselhos de Saúde e a responsabilidade cidadã. Ciência \& Saúde Coletiva. Rio de Janeiro, v. 3, n. 1, p. 18-19, 1998.

BOMBARO LO, Félix. Onírico y Real......através del concepto de participación social en América Latina y el Caribe (medio siglo en su nombre....). Buenos Aires, 2000. Disponível em: <www.organizacionpoleas.net>. Acesso em: 18 de ago. de 2006.

BRASIL. Congresso. Lei 8.142 de 28 de dezembro de 1990. Dispõe sobre a participação da comunidade na gestão do Sistema Ú nico de Saúde - SUS e sobre as transferências intergovernamentais de recursos financeiros na área de saúde e dá outras providências. 1990.

CAPES - CO ORDENAÇÃO DE APERFEIÇO AM ENTO DE PESSO AL DE NÍVEL SUPERIO R. Q ualis. Disponível em: < http://qualis.capes.gov.br>. Acesso em: 29 de set. de 2005.

CARVALHO, Antônio Ivo de. Participação e controle social em saúde: recapitulando idéias e práticas. In: CARVALHO, Antônio Ivo de. Conselhos de Saúde no Brasil: Participação Cidadã e Controle Social. Rio de Janeiro: FASE / IBAM , 1995. p. 8-28. 
CARVALHO, Antônio Ivo de. O s Conselhos de Saúde, Participação Social e Reforma do Estado. Ciência e Saúde Coletiva. Rio de Janeiro, v. 3, n. 1, p. 23 - 25, 1998.

COHN, Amélia; ELIAS, Paulo e JACO BI, Pedro. Participação popular e gestão de serviços de saúde: um olhar sobre a experiência do município de São Paulo. Saúde em Debate, Rio de Janeiro, n. 38, p. 90-93, 1993.

CORTES, Soraya M aria Vargas. As origens da participação na área da saúde. Saúde em Debate, Londrina, n. 51, p. 30-37, 1996 (a).

CORTES, Soraya M aria Vargas. Céticos e esperançosos: perspectivas da literatura sobre participação e governança. Porto Alegre, janeiro de 2005 (mimeo).

CORTES, Soraya Maria Vargas. Conselhos Municipais de Saúde: a possibilidade dos usuários participarem e os determinantes da participação. Ciência \& Saúde Coletiva. Rio de Janeiro, v. 3, n. 1, p. 5-17, 1998 (a).

CORTES, Soraya Maria Vargas. Conselhos M unicipais de Saúde: Avaliações Otimistas e Pessimistas. Ciência e Saúde Coletiva. Rio de Janeiro, v. 3, n. 1, p. 33 35, 1998. (b).

CORTES, Soraya M aria Vargas. Construindo a possibilidade da participação dos usuários: conselhos e conferências no Sistema Ú nico de Saúde. Sociologias, Porto Alegre, ano 4, n. 7, p. 18-49, 2002.

CORTES, Soraya M aria Vargas. Fóruns participatórios na área de saúde: teorias do Estado, participantes e modalidades de participação. Saúde em Debate, Rio de Janeiro, n. 49-50, p. 73-79, 1996 (b).

COSTA, Ana Maria e NORO NHA, José Carvalho de. Controle Social na Saúde: construindo a Gestão Participativa. Saúde em Debate. Rio de Janeiro, v. 27, n. 65, p. 358-363, 2003.

DAL POZ, Mario Roberto e PIN HEIRO, Roseni. A Participação dos Usuários nos Conselhos M unicipais de Saúde e seus Determinantes. Ciência e Saúde Coletiva. Rio de Janeiro, v. 3, n. 1, p. 28 - 30, 1998.

DONZELOT, Jacques; EPSTEIN, Reanud. Démocratie et participation: l'exemple de la renovation urbaine. Esprit, jul. 2006, 5-34.

FERN ANDES, Rubem César. Privado porém público: o terceiro setor na América Latina. 2ำ edição. Rio de Janeiro: Relume Dumará, 1994.

GASCÓN, Silvia; TAMARGO, María del Carmen e CARLES, Mónica. Marco Conceptual Y Metodológico sobre Participación Ciudadana en Salud en el MERCO SU R Ampliado. Fundacion ISALU D, primer informe de avance, fev. 2005. 
GERSCHMAN, Silvia. Conselhos Municipais de Saúde: atuação e representação das comunidades po pulares. Cadernos de Saúde Pública, Rio de Janeiro, v. 20, n. 6, p. 1670 - 1681, 2004.

GO NÇALVES, M aria de Lourdese ALM EIDA, M aria Cecília Puntel de. Construindo o controle social e a cidadania em uma experiência concreta: o conselho municipal de saúde (CMS) de Ribeirão Preto (SP). Saúde em Debate, Rio de Janeiro, v. 26, n. 61, p. 167-175, 2002.

HUNTIN GTO N, Samuel P. e N ELSO N, Joan. No Easy Choice: Political Participation in Developing Countries. Harvard University Press, 1976.

LABRA, Maria Eliana e FIGUEIRED O , Jorge St Aubyn de. Associativismo, participação e cultura cívica. 0 potencial dos conselhos de saúde. Ciência \& Saúde Coletiva, Rio de Janeiro, v. 7, n. 3, p. 537 - 547, 2002.

LESSA, Renato. As Razões da Poliarquia. Jornal de Resenhas. Folha de São Paulo, São Paulo, 8 nov. 1997.

MACPHERSON, Crawford Brough. The Life and Times of Liberal Democracy. Toronto: Oxford University Press, 1977.

O 'DWYER, Gilson Cantarino e M OYSÉS, Neuza M. N. Conselhos M unicipais de Saúde: $O$ Direito de Participação da Sociedade Civil? Ciência e Saúde Coletiva. Rio de Janeiro, v. 3, n. 1, p. 26 - 27, 1998.

PED RO SA, José Ivo dos Santos. A construção do significado de controle social com conselheiros de saúde no Estado do Piauí, Brasil. Cadernos de Saúde Pública. Rio de Janeiro, v. 13, n. 4, p. 741-748, 1997.

PED RO SA, José Ivo dos Santos. Dilemas e Perspectivas do SU S no Estado do Piauí: uma conversa com conselheiros. Saúde em Debate. Rio de Janeiro, n. 49-50, p. 28-32, 1996.

PESSO TO, U mberto Catarino; NASCIM ENTO, Paulo Roberto do e HEIM AN N, Luiza Sterman. A gestão semiplena e a participação popular na administração da saúde. Cadernos de Saúde Pública. Rio de Janeiro, v. 17, n. 1, p. 89 - 97, 2001.

PRATA, Luiz; GARCIA, A. L. A.; LEITÃO, C. A. e HEN RIQ UE, M. M. Conselho de U nidade de Saúde - uma estratégia de fortalecimento do Controle Social no município de M anhuaçu (M G). Divulgação em Saúde para Debate, Rio de Janeiro, n. 30, p. 107-111, 2004.

QUIRINO, Célia Galvão. "Tocqueville: sobre a liberdade e a igualdade", in: W EFFO RT, Francisco C. (org). Os Clássicos da Política. Vol 2. São Paulo: Ática, 13a edição, 2005. 
RO USSEAU, Jean Jacques. "D o Contrato Social, Livro III, Capítulo XII" in: WEFFO RT, Francisco C. (org). Os Clássicos da Política. Vol 1. São Paulo: Ática, 13ạ edição, 2005.

SANTO S, Boaventura de Souza. "O social e o político na transição pós-moderna". Lua Nova, São Paulo, n. 31, 1993.

SILVA, Ionara Ferreira da. 0 processo decisório nas instâncias colegiadas do SU S e o controle social no estado do Rio de Janeiro. Saúde em Debate. Rio de Janeiro, v. 28, n. 67, p. 130-139, 2004.

SILVA, Geovani Gurgel Aciole da; EGYDIO, Maria Vitoria Real M endes e SO UZA, Martha Coelho de. Algumas considerações sobre o controle social no SUS: usuários ou consumidores? Saúde em Debate, Rio de Janeiro, v. 23, n. 53, p. 37-42, 1999.

SO UZA, Waldir da Silva. A autonomia e a responsabilidade revisitada: Ivan Illich e a higiomania contemporânea. Ciência \& Saúde Coletiva, Rio de Janeiro, v. 9, n. 4, p. 1082-1083, 2004.

VALLA, Victor Vincent. Comentários a "Conselhos M unicipais de Saúde: A Possibilidade dos U suários Participarem e os D eterminantes da Participação". Ciência e Saúde Coletiva, Rio de Janeiro, v. 3, n. 1, p. 31-32, 1998.

VAND ERLEl, M aria leda Gomes e W ITT, Regina Rigatto. Conselhos de Saúde: espaços de participação social, constituição de sujeitos políticos e co-produção de sujeitos coletivos. Saúde em Debate. Rio de Janeiro, v. 27, n. 64, p. 131 - 137, 2003.

VIAN NA, M aria Lúcia Teixeira Werneck. A administração do Conselho Monetário Nacional 1964 - 1974. Petrópolis: Vozes, 1987.

VIAN NA, Maria Lúcia Teixeira Werneck. 0 Postulado da obrigação política e suas justificativas ideológicas na teoria clássica. Rio de Janeiro: U niversidade Federal do Rio de Janeiro / Instituto de Economia Industrial, 1989.

WENDHAUSEN, Águeda e CAPONI, Sandra. O diálogo e a participação em um conselho de saúde em Santa Catarina, Brasil. Cadernos de Saúde Pública, Rio de Janeiro, v. 18, n. 6, p. 1621-1628, 2002.

ZANARDI, Reinaldo César e CO RDO NI Jr, Luiz. A participação social na construção do modelo assistencial de saúde de Londrina. Revista Espaço para a Saúde, Londrina, v.6, n.1, p. 7-15, 2004. 